\title{
Molecular and virulence characteristics of an outer membrane-associated RTX exoprotein in Pasteurella pneumotropica
}

\author{
Hiraku Sasaki ${ }^{1 *}$, Hiroki Ishikawa ${ }^{2}$, Toru Sato ${ }^{3}$, Satoshi Sekiguchi $^{4}$, Hiromi Amao ${ }^{4}$, Eiichi Kawamoto ${ }^{1}$,
} Tetsuya Matsumoto ${ }^{2}$ and Kazuhiko Shirama ${ }^{3}$

\begin{abstract}
Background: Pasteurella pneumotropica is a ubiquitous bacterium that is frequently isolated from laboratory rodents and causes various clinical symptoms in immunodeficient animals. Currently two RTX toxins, PnXIA and PnxlIA, which are similar to hemolysin-like high-molecular-weight exoproteins are known in this species. In this study, we identified and analyzed a further RTX toxin named PnxIIIA and the corresponding type I secretion system.

Results: The RTX exoprotein, PnxIIIA, contains only a few copies of the RTX repeat-like sequence and 3 large repeat sequences that are partially similar to the outer membrane protein found in several prokaryotes. Recombinant PnxIIIA protein ( $\mathrm{PPnx}$ IIIA) was cytotoxic toward J774A.1 mouse macrophage cells, whereas cytotoxicity was attenuated by the addition of anti-CD11a monoclonal antibody. rPnxIIIA could bind to extracellular matrices (ECMs) and cause hemagglutination of sheep erythrocytes. Binding was dependent on the 3 large repeat sequences in PnxIIIA. Protein interaction analyses indicated that PnxIIIA is mainly localized in the outer membrane of P. pneumotropica ATCC 35149 in a self-assembled oligomeric form. PnxllIA is less cytotoxic to J774A.1 cells than PnxIA and PnxllA.
\end{abstract}

Conclusions: The results implicate that PnxllIA is located on the cell surface and participates in adhesion to ECMs and enhanced hemagglutination in the rodent pathogen $P$. pneumotropica.

\section{Background}

Pasteurella pneumotropica is a Gram-negative rod-shaped bacterium that is frequently isolated from the upper respiratory tract of laboratory rodents. This bacterium is a major causative agent of opportunistic infection in rodents, and almost all infected immunocompetent rodents exhibit unapparent infection. An earlier study reported that coinfection by $P$. pneumotropica and Mycoplasma pulmonis causes pneumonia in specific pathogenfree mice [1]. A recent study reported that P. pneumotropica infection disturbs the inflammation responses in immunocompetent mice [2]. In immunodeficient rodents, however, $P$. pneumotropica infection leads to various serious diseases such as lethal pneumonia and sepsis. It is

\footnotetext{
* Correspondence: h-sasaki@tokyo-med.ac.jp

${ }^{1}$ Animal Research Center, Tokyo Medical University, Shinjuku, Tokyo, Japan Full list of author information is available at the end of the article
}

well known that coinfection with Pneumocystis carinii and $P$. pneumotropica leads to fatal pneumonia in B cell-deficient mice [3,4]. In mice lacking functional MHC II, Tlr4, and Nramp1 genes, experimental challenge with P. pneumotropica results in pulmonary infections $[5,6]$. Furthermore, orbital abscesses were caused by P. pneumotropica infection in Cd28-mutated mice [7]. In laboratory rodents, these infections could be effectively treated with antibiotics [8-10], and hysterotomy and embryo transfer are known to be the most effective treatments for eliminating P. pneumotropica completely [8]. However, both treatments are time-consuming and require special facilities and equipment. Therefore, to prevent $P$. pneumotropica infection in laboratory rodents, it is necessary to periodically perform microbiological monitoring of laboratory rodents and maintain a clean environment in the rodent colony. To perform microbiological monitoring and prevent infection,
Ciomed Central 
it is important to clarify the virulence factors and pathogenicity of $P$. pneumotropica.

The phenotypic characteristics related to the virulence of $P$. pneumotropica are hemagglutination and hemolysis [11-13]. Two recently named exoproteins, PnxIA and PnxIIA, both of which have C-terminal primary structures similar to the repeat in structural toxin (RTX) toxins, have been identified and characterized as hemolysin-like proteins in P. pneumotropica [13]. RTX toxins have many copies of glycine-rich sequences, and these toxins have been identified in many species of Gram-negative bacterium, including Pasteurellaceae, Enterobacteriaceae, and Vibrionaceae [14-17]. Many RTX toxins are reportedly capable of lysing erythrocytes; thus, RTX toxins function as hemolysins [14,17]. In addition, several RTX toxins act as leukotoxins and disrupt actin cytoskeletons. LtxA produced by the periodontopathogen Aggregatibacter actinomycetemcomitans specifically acts on human polymorphonuclear leukocytes and macrophages while concurrently lysing erythrocytes to acquire iron [18-21]. Apx toxins (ApxIA and ApxIIA) and lipopolysaccharides (LPSs) are the major virulence factors for the porcine pathogen Actinobacillus pleuropneumoniae, and the Apx-LPS complex promotes cytotoxicity toward porcine alveolar macrophages [22]. Furthermore, the Vibrio cholerae multifunctional autoprocessing RTX toxin, which acts on cellular actin protomers by cross-linking, disrupts the actin cytoskeleton of cells [23-26]. As reported in recent studies, RTX toxins act on a variety of cells and cellular matrices and are considered to have various effects on host cells. Therefore, elucidating the functions of RTX toxins may lead to a better understanding of the mechanisms by which infectious agents cause infection.

In a previous study, we identified additional members of the RTX toxin family, namely, PnxIA and PnxIIA, in P. pneumotropica [13]. Details about their functions and cytotoxicity, excluding their effects on sheep and mouse erythrocytes, remain to be clarified, and it is important to examine these proteins to prove that there are additional genes that code for proteins that are similar to RTX toxins; this is important for elucidating P. pneumotropica pathogenicity. In this study, we identified a third gene encoding an RTX protein and characterized it in terms of its in vitro cytotoxicity and hemolytic activity. To understand the function of this RTX protein, we attempted to determine its virulence characteristics based on its predicted primary structure.

\section{Results}

Identification of the third gene encoding an RTX protein A previous study revealed that $P$. pneumotropica carries 2 genes encoding hemolysin-like proteins that are similar to the RTX toxins PnxIA and PnxIIA [13]. Although both structural protein-coding genes could be detected using Southern hybridization or PCR, several unspecific genes were also detected when the gene coding for PnxIIA was targeted for detection by using PCR techniques in reference strains and wild-type strains of P. pneumotropica (data not shown). In this study, this heterogenic PCR product was cloned, and the inserts of the resultant plasmid pTAC-PX3 were sequenced. The sequence of the inserts was similar to that of the glycine-rich regions in pnxIIA; however, the detailed sequence indicated the existence of an additional gene that encodes a protein similar to the RTX toxin. Subsequently, we sequenced the uninserted regions from the genomic DNA of P. pneumotropica ATCC 35149 by using a previously constructed clone library [13] and inverse PCR. Approximately $14 \mathrm{~kb}$ of related genes, including 5 putative open reading frames (ORFs), were finally identified (Figure 1A). To predict the functions of the gene products, the deduced amino acid sequence of each gene was analyzed on the basis of hidden Markov model (HMM) profiles with a protein BLAST search [27] or the Pfam database [28]. The pnxIII operon comprised the genes encoding 3 functional component proteins, namely, the OmpA-like protein, RTX exoprotein, and type I secretion system component proteins (Figure 1A). The deduced amino acid sequences of $t o l C$, pnxIIIB, and pnxIIID were similar to that of the putative outer membrane (OM) efflux protein of Neisseria sicca ATCC 29256 (GenBank accession no. ZP_05317789) with $68 \%$ similarity and $91 \%$ coverage, the LapA secretion ATP-binding protein of Neisseria mucosa ATCC 25996 (ZP_05976520) with 86\% similarity and 99\% coverage, and a membrane fusion protein of Simonsiella muelleri ATCC 29453 (ZP_06753782) with 87\% similarity and $100 \%$ coverage, respectively. The proteins from the 3 ORFs were indicated to form a type I secretion system that transports the RTX protein across the bacterial inner membrane (IM) and OM and finally exports it into extracellular space.

The pnxIIIE gene product contains the OmpA domain (Pfam reference: accession no. PF00691) in the C-terminus and is $54 \%$ similar to the OM protein A of Cardiobacterium hominis ATCC 15826 (ZP_05705729), with 84\% coverage.

Although the protein BLAST search yielded no highly similar proteins, the deduced amino acid sequence of pnxIIIA was partially similar (46\%) to the RTX family exoprotein of uropathogenic E. coli (UPEC) CFT073 [29] (NP_752300), i.e., 59\% coverage. PnxIIIA is believed to be an essential cytotoxic protein of the structural RTX toxin.

Figure 1B shows the putative domains and repeat sequence in the primary structure of PnxIIIA. PnxIIIA did not have any significant identical conserved domains 


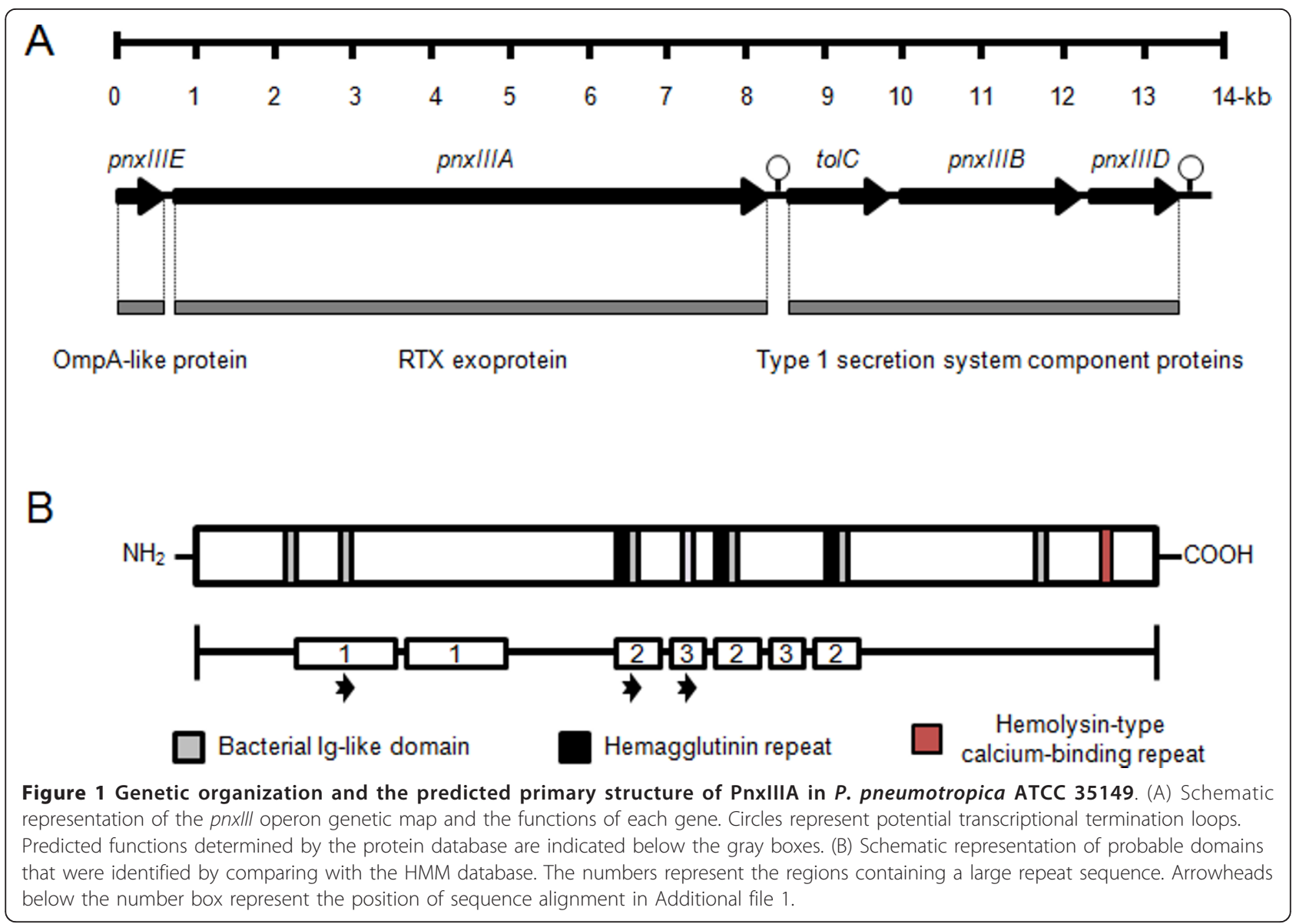

in the Pfam database; however, several partial sequences that were not significantly similar to conserved domains were identified in the HMM database. In brief, several groups of bacterial immunoglobulin (Ig)-like domains (Pfam reference: accession no. PF05345, PF02369, PF02368, PF07532, and PF10648) and a hemagglutinin repeat (PF05594) were scattered in the primary sequence of PnxIIIA, and a hemolysin-type calciumbinding repeat (PF00353) identical to nonapeptides of the RTX repeat sequence in the $\mathrm{C}$-terminal half was present (Figure 1B). In particular, only 1 copy of amino acid residues in position 2319-2327 (LDGGDGNDT) was found to be identical to the RTX sequence; otherwise, 2 RTX-like sequences were found in positions 2114-2122 (NFGGMGVSN; alternate amino acid residues are italicized) and 2377-2384 (IKGGT-NDT; the missing amino acid residue is indicated with a hyphen). PnxIIIA was also found to have a unique feature: 3 regions with large repeat sequences existed, and the amino acid sequences in these regions were similar to the repeat sequences of the extracellular protein toxin identified in various prokaryotes, including important pathogens (see multiple alignments in Additional file 1).
Of these, except for the unknown function of the RTX exoprotein and hemolysin-type calcium-binding protein, almost similar proteins were predicted to be localized in the OM fraction and to function as adhesive proteins.

\section{Cytotoxicity of rPnxIIIA}

To assess the virulence characteristics of PnxIIIA, we determined its cytotoxicity toward J774A.1 mouse macrophage cells by using soluble rPnxIIIA. With increasing rPnxIIIA concentrations, the cytotoxicity as determined from the amount of lactose dehydrogenase (LDH) released by the cells was increased during a 24-h incubation (Additional file 2). In addition, we examined and compared the cytotoxicity of 3 recombinant RTX proteins identified in P. pneumotropica toward J774A.1 cells. During a 4-h incubation, native rPnxIA, rPnxIIA, and rPnxIIIA exhibited 55.2\% $\pm 7.2 \%, 45.2 \% \pm 3.1 \%$ and $29.8 \% \pm 7.1 \%$ cytotoxic to J774A.1 cells, respectively. Compared with previously found RTX proteins, rPnxIIIA was significantly less cytotoxic than rPnxIA and rPnxIIA $(P<0.05)$. Several RTX toxins have been recognized in a species-specific manner, and are found to be cytotoxic to leukocyte function-associated antigen-1 (LFA-1)-bearing 
cells [30-32]. To characterize the cytotoxicity of PnxIIIA toward J774A.1 mouse macrophage cells, it is important to assess the effect of the presence of the LFA-1 receptor in macrophage cells. Furthermore, we employed comparative analysis of PnxIIIA cytotoxicity by using parent J774A.1 cells and anti-CD11a monoclonal antibody (MAb)-treated J774A.1 cells as a neutralizing antibody. Figure 2 shows the changes in cytotoxicity of both J774A.1 cells and anti-CD11a MAb-treated cells cultured with $1.0 \mu \mathrm{g} / \mathrm{ml} \mathrm{rPnxIIIA}$. During a 24-h incubation, approximately $20-50 \%$ of cytolysis was inhibited by the addition of anti-CD11a MAb. These results indicate that the presence of the LFA-1 receptor may be required for rPnxIIIA cytotoxicity toward J774A.1 cells.

\section{ECM-binding ability and hemagglutination}

Figures $3 \mathrm{~A}$ to $3 \mathrm{D}$ show the changes in absorbance at $620 \mathrm{~nm}$ (A620) when rPnxIIIA was gradually added to the ECM-coated 96-well plate; the changes in absorbance were determined by an enzyme-linked immunosorbent assay (ELISA). rPnxIIIA adhered to all tested rodent ECMs, with adhesion increasing as the rPnxIIIA concentration increased. In particular, the A620 of collagen type I (Figure 3A) was highest among the tested rodent ECMs, followed by that of collagen type II (Figure 3B), which was the second most adhesive ECM at a concentration of $50 \mu \mathrm{g} / \mathrm{ml}$. Although the A620 values of collagen type IV and laminin were lower than those of collagen type I and type II, rPnxIIIA was

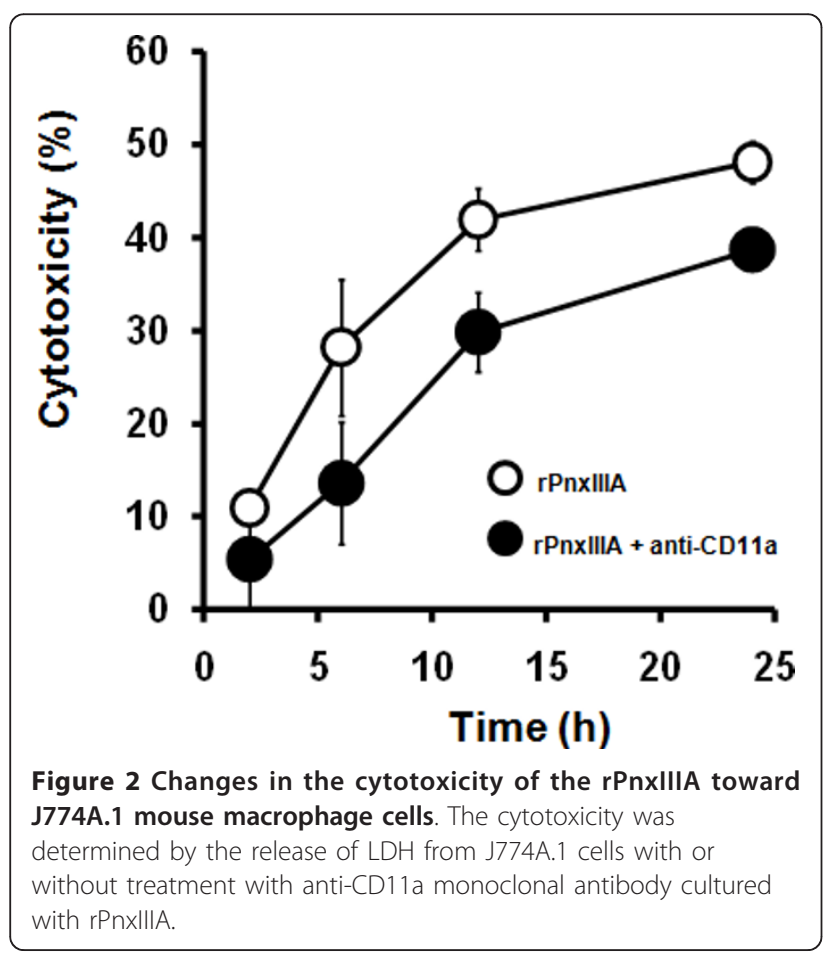

confirmed to bind to both ECMs at higher concentrations (Figure $3 \mathrm{C}$ and $3 \mathrm{D}$ ). These results indicate that rPnxIIIA can bind to rodent ECMs.

When compared with the domains in the HMM database, several PnxIIIA domains have large repeat sequences that contain the hemagglutinin repeat in the primary sequence. rPnxIIIA was subjected to a hemagglutination assay with washed sheep erythrocytes. Figure $3 \mathrm{E}$ shows the results of the hemagglutination assay with rPnxIIIA. Hemagglutination of sheep erythrocytes was observed at rPnxIIIA concentrations exceeding $12.5 \mu \mathrm{g} /$ $\mathrm{ml}$, indicating that rPnxIIIA participates in the hemagglutination of sheep erythrocytes.

We also measured the hemoglobin released from the sheep erythrocytes when they were cultured with rPnxIIIA; however, rPnxIIIA did not exhibit typical hemolytic activity, indicating that rPnxIIIA is less involved in hemolysis.

\section{Characterization of deletion mutants of rPnxIIIA variants}

To clarify the role of large repeat sequences in the functions of PnxIIIA, we generated soluble rPnxIIIA and deletion mutants of rPnxIIIA variants. rPnxIIIA, rPnxIIIA $_{209}$, rPnxIIIA 197 , and rPnxIIIA ${ }_{151}$ essentially contained $255 \mathrm{kDa}, 209 \mathrm{kDa}, 197 \mathrm{kDa}$, and $151 \mathrm{kDa}$ of the parent PnxIIIA, respectively (Additional file 3A).

To compare the binding ability of the rPnxIIIA variants, we performed binding assays with collagen type I coated on the 96-well plate when $10 \mu \mathrm{g} / \mathrm{ml}$ of the rPnxIIIA variants were applied. The A620 of wild-type rPnxIIIA was $0.55 \pm 0.05$, compared to $0.30 \pm 0.06,0.27 \pm 0.01$, and 0.26 \pm 0.04 for that of $\mathrm{rPnxIIIA}_{209}, \mathrm{rPnxIIIA}_{197}$, and rPnxIIIA $_{151}$, respectively (Additional file $3 \mathrm{~B}$ ). Almost all A620s of the deletion mutant proteins were lower than that of the parent rPnxIIIA. These results indicate that rPnxIIIA can bind to ECMs and that its lack of repeat sequences reduces its ability to bind ECMs.

We subjected the rPnxIIIA variants to a hemagglutination assay with washed sheep erythrocytes. Although the deletion mutant protein $\mathrm{rPnxIII}_{209}$ promoted hemagglutination at the same concentration as that of rPnxIIIA, more than $25 \mu \mathrm{g} / \mathrm{ml}$ of both PPnxIIIA $_{197}$ and rPnxIIIA $_{151}$ were required for hemagglutination (Additional file $3 \mathrm{C}$ ). Although exact differentiation among the rPnxIIIA variants was not observed in hemagglutination, these results indicate that rPnxIIIA plays a role in hemagglutination and that the repeat sequences located in the $\mathrm{C}$-terminal portion are necessary for enhanced hemagglutination.

\section{Localization and interaction of PnxIIIA}

Figure 4A shows the results of the Western blotting analysis of fractionated P. pneumotropica ATCC 35149 cells with anti-rPnxIIIA rabbit IgG. Signals of proteins 

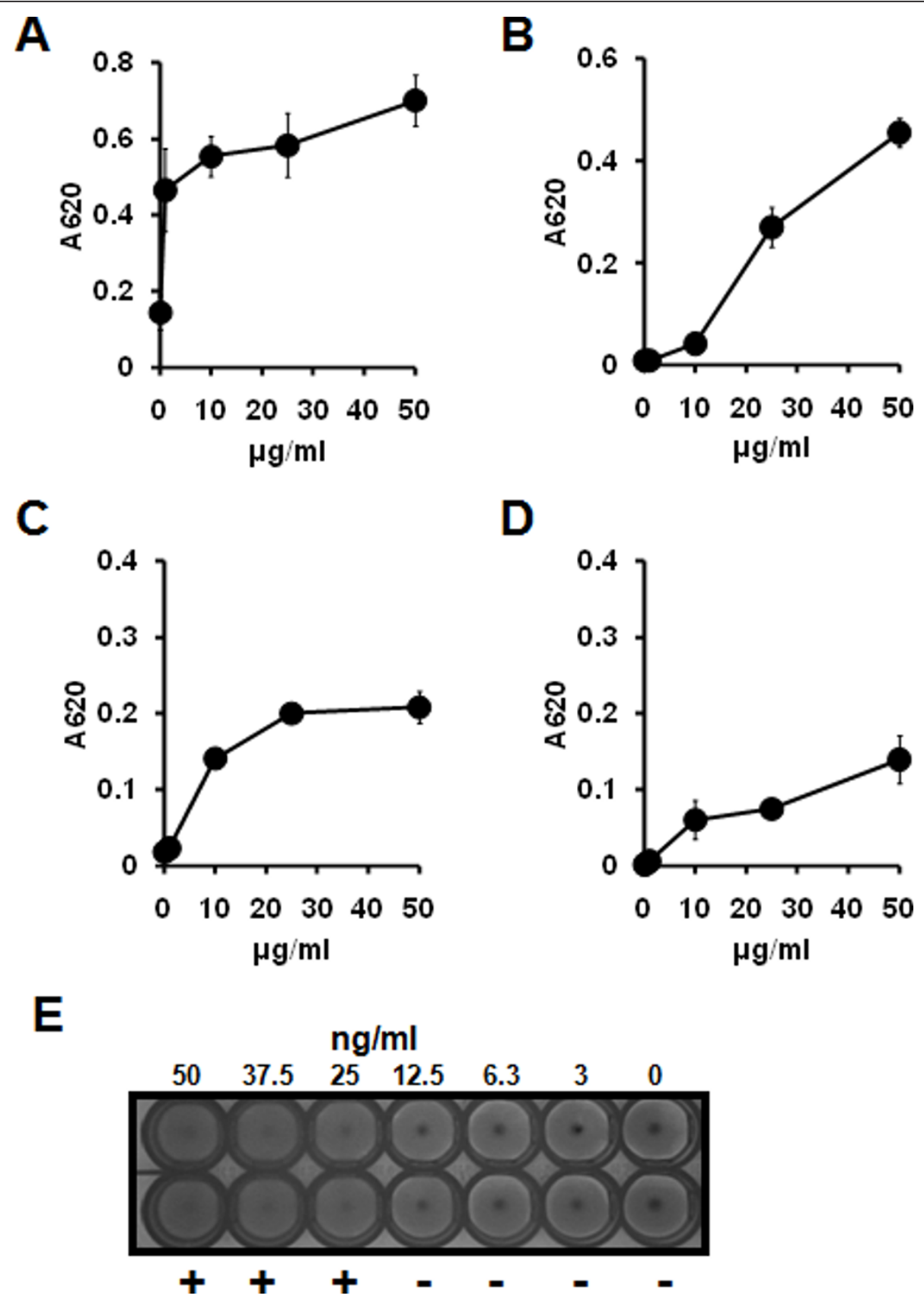

Figure 3 The binding ability and hemagglutination activity of the rPnxIIIA. The binding ability of rPnxllIA to the ECMs as determined by ELISA (A to D) and hemagglutination activity of the rPnxllIA with sheep erythrocytes (E). Changes in the ability of different concentrations of rPnxIIIA to bind to the rat collagen type I (A), rat collagen type II (B), mouse collagen type IV (C), and mouse laminin (D), as determined by measuring the A620. Changes in the hemagglutination activity of different concentration of rPnxlllA with sheep erythrocytes (E).

of approximately $250 \mathrm{kDa}$ in size were detected in all fractions; however, in the case of the OM fraction, the intensity of the signal was strong and located above the $250-\mathrm{kDa}$ marker and other fractions. This result was also observed when the boiling time was increased to 20 min before sodium dodecyl sulfate-polyacrylamide gel electrophoresis (SDS-PAGE) and a redox reagent or denaturant such as dithiothreitol or urea was added to the $\mathrm{OM}$ fraction, as the position of the signal remained unchanged. Therefore, PnxIIIA appeared to tightly bind to proteins in the OM fraction. One candidate that interacts with PnxIIIA in the OM fraction is the gene product of pnxIIIE. Figure 4B shows the results of the Western blotting analysis of fractionated cells with 


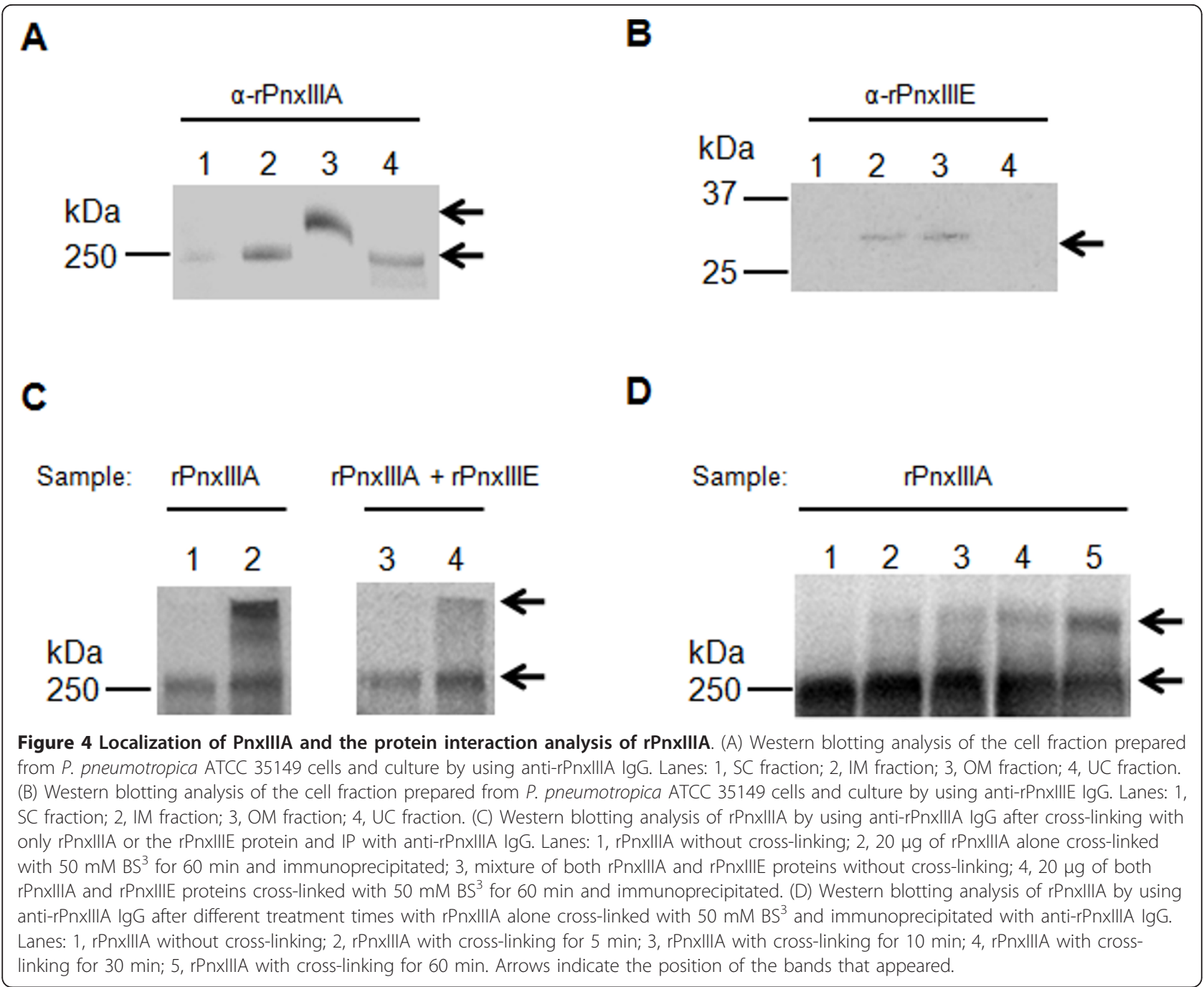

anti-rPnxIIIE IgG. Signals appeared in the IM and OM fractions, and the estimated protein size was assumed to be the expected size of $30 \mathrm{kDa}$. These results may indicate that PnxIIIE exists mainly in the IM and OM fraction as a monomeric protein. Subsequently, we examined the in vitro interaction between rPnxIIIA and rPnxIIIE by using a soluble protein cross-linker, $\mathrm{BS}^{3}$. The reaction mixture was then pulled down via immunoprecipitation (IP) by using anti-rPnxIIIA IgG. Figure $4 \mathrm{C}$ shows the results of the Western blotting analysis of cross-linking and the IP products detected with antirPnxIIIA IgG. The signal was detected at $250-\mathrm{kDa}$ when only rPnxIIIA or rPnxIIIA and rPnxIIIE was used alone without cross-linking (Figure 4C, lane 1 and 3). However, the positions of their signals appeared higher than that of rPnxIIIA together with the parent $250-\mathrm{kDa}$ rPnxIIIA when only rPnxIIIA or rPnxIIIA and rPnxIIIE was used after treatment with $50 \mathrm{mM} \mathrm{BS}^{3}$ (Figure $4 \mathrm{C}$, lane 3 and 4). Furthermore, a shift of the signals was observed with increasing reaction time when only rPnxIIIA was used after treatment with $\mathrm{BS}^{3}$ (Figure 4D). These results indicate that rPnxIIIA interacts itself, and self-assembled oligomerized PnxIIIA is located in the OM fraction in P. pneumotropica ATCC 35149.

Figure 5 shows immunoelectron microscopy images of P. pneumotropica ATCC 35149 cells. Anti-rPnxIIIA IgG bound mainly to the cell surface, and few cellular and extracellular substances were gold-labeled, indicating that PnxIIIA is habitually localized on cell surfaces.

\section{Ability of adherence, hemagglutination, and cytotoxicity in reference strains}

Initially, we performed Southern blotting analysis for detecting partial sequences of pnxIIIA. Only genomic DNA from P. pneumotropica CCUG 26450 was confirmed to include the partial gene containing the RTX repeat (Additional file 4); however, numerous signals including putative unspecific signals appeared using the 


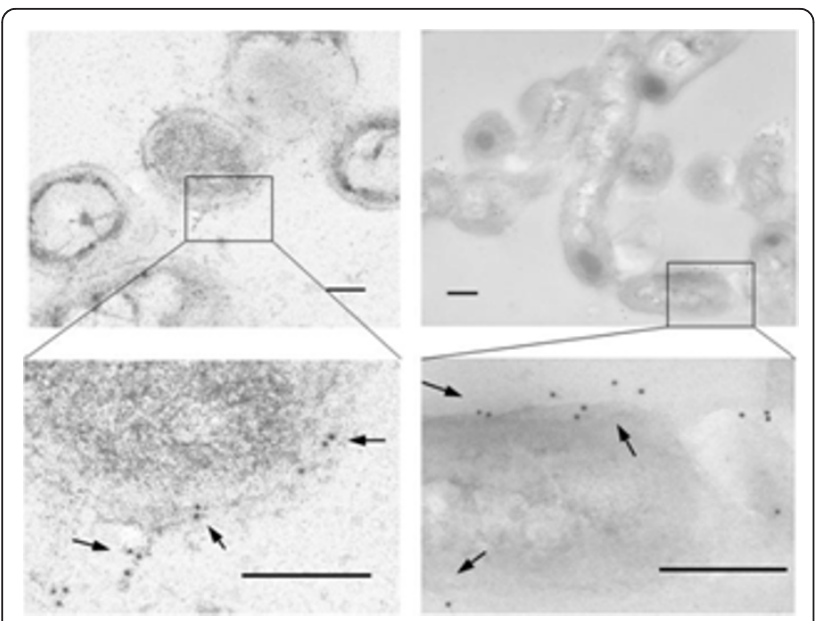

Figure 5 Transmission electron micrographs of $P$. pneumotropica ATCC 35149 cells by immunoelectron microscopy with antirPnxIIIA IgG. Transmission electron micrographs of the $P$.

pneumotropica ATCC 35149 cells that were first reacted with antirPnxIIIA IgG and then labeled with gold particles (10-nm) conjugated with rabbit lgG antibody. Arrows indicate the areas where gold labeling appeared on the cell surface. Left panel, cross-section of the bacterial cell. Right panel, longitudinal section of the bacterial cell. $\operatorname{Bar}=0.2 \mu \mathrm{m}$.

probes targeting the gene encoding $\mathrm{N}$-terminal portion of PnxIIIA. These results indicate that the gene encoding PnxIIIA is heterogenic and diversified. Subsequently, we performed Western blotting analysis of total protein obtained from cultured cells with anti-rPnxIIIA. Although PnxIIIA was detected in the 5 reference strains of P. pneumotropica by Western blotting, the estimated size and intensity of the detected signals were varied among the strains (Figure 6A). In brief, the molecular weight of the detected signals obtained from ATCC 12555 and CCUG 36632 was approximately $250 \mathrm{kDa}$, whereas those obtained from CCUG 262450 and CCUG 26451 were less than $250 \mathrm{kDa}$. Furthermore, the signals from both ATCC 35149 and CCUG 26450 had higher intensity than those of the other reference strains. The A490 values determined by whole-cell binding assays with the collagen type I of the PnxIIIAproducing strains were significantly higher than that of CCUG 26453, which was not confirmed to produce PnxIIIA $(P<0.05$; Figure 6B). Hemagglutination activity was clearly observed in the 5 reference strains, whereas CCUG 26453 exhibits insignificant activity (Figure 6C). Although the existence of PnxIIIA was confirmed to participate in the activity of adherence and hemagglutination, these activities may be varied among the strains. Furthermore, the cytotoxicity of reference strains toward J774A.1 cells was examined (Figure 6D). Strains ATCC 35149, ATCC 12555, and CCUG 36632 exhibited more than $70 \%$ cytotoxicity; the other strains exhibited less than $50 \%$ cytotoxicity. Although the cytotoxicity of each strain did not absolutely coincide with those of the strains that produce PnxIIIA, strain CCUG 26453, which was not confirmed to produce PnxIIIA, was demonstrated to be less cytotoxic toward J774A.1 cells. These results also indicate that rodent isolates were found to have binding and hemagglutination activities; on the other hand, P. pneumotropica CCUG 26453, which was recorded to be isolated from birds, was not confirmed to have these activities (Table 1).

\section{Discussion}

In this study, we identified and characterized a third gene that encodes an RTX exoprotein in P. pneumotropica. A known protein that is similar to PnxIIIA is the RTX exoprotein, which was identified in a UPEC strain [29]. Lloyd et al. [33] reported that a mutant strain in which the gene encoding this RTX exoprotein was deleted colonized bladders and kidneys less efficiently than the wild-type UPEC strain. These results indicate that this RTX toxin may participate in bacterial colonization. To characterize the virulence properties of PnxIIIA, we focused on its adhesion and hemagglutination activities as well as its cytotoxicity. For instance, $100-500 \mathrm{ng} / \mathrm{ml}$ recombinant CyaA from Bordetella pertussis lysed approximately $100 \%$ of murine monocytes over a 4-h period [34]. Although the conditions were different, PnxIIIA was assumed to be weakly cytotoxic compared to the RTX toxin, which is highly toxic.

Several RTX toxins that act as leukotoxins reportedly bind to $\beta_{2}$-integrin LFA-1 (CD11a/CD18) on speciesspecific leukocytes [30-32,35]. LFA-1 is expressed on the cell surface as a glycoprotein composed of the $\alpha$ subunit of CD11 and the $\beta$ subunit of CD18. In the case of LktA produced by Mannheimia haemolytica, which is the principal pathogen of bovine respiratory diseases complex, can bind to the bovine CD11a of LFA-1 [31]. LtxA produced by $A$. actinomycetemcomitans recognizes the $\beta$-propeller domain of human CD11a [36]. The cytotoxicity of rPnxIIIA toward J774A.1 cells was successfully attenuated by the addition of anti-CD11a MAb, which can react to mouse CD11a as a neutralizing antibody, suggesting that the $\alpha$ subunit of mouse LFA-1 may be required for its cytotoxicity toward J774A.1 cells. The detailed mechanisms underlying CD11a mediated PnxIIIA cytolysis need to be clarified in future studies.

One of the features of this high-molecular-weight protein is that it has 2-3 different copies of 3 large repeat sequences. These copies, although not completely identical, are highly similar and contain several bacterial Ig-like domains and a hemagglutination repeat. The deletion mutant proteins were observed to bind less to rodent ECMs compared with the parent rPnxIIIA. All 3 


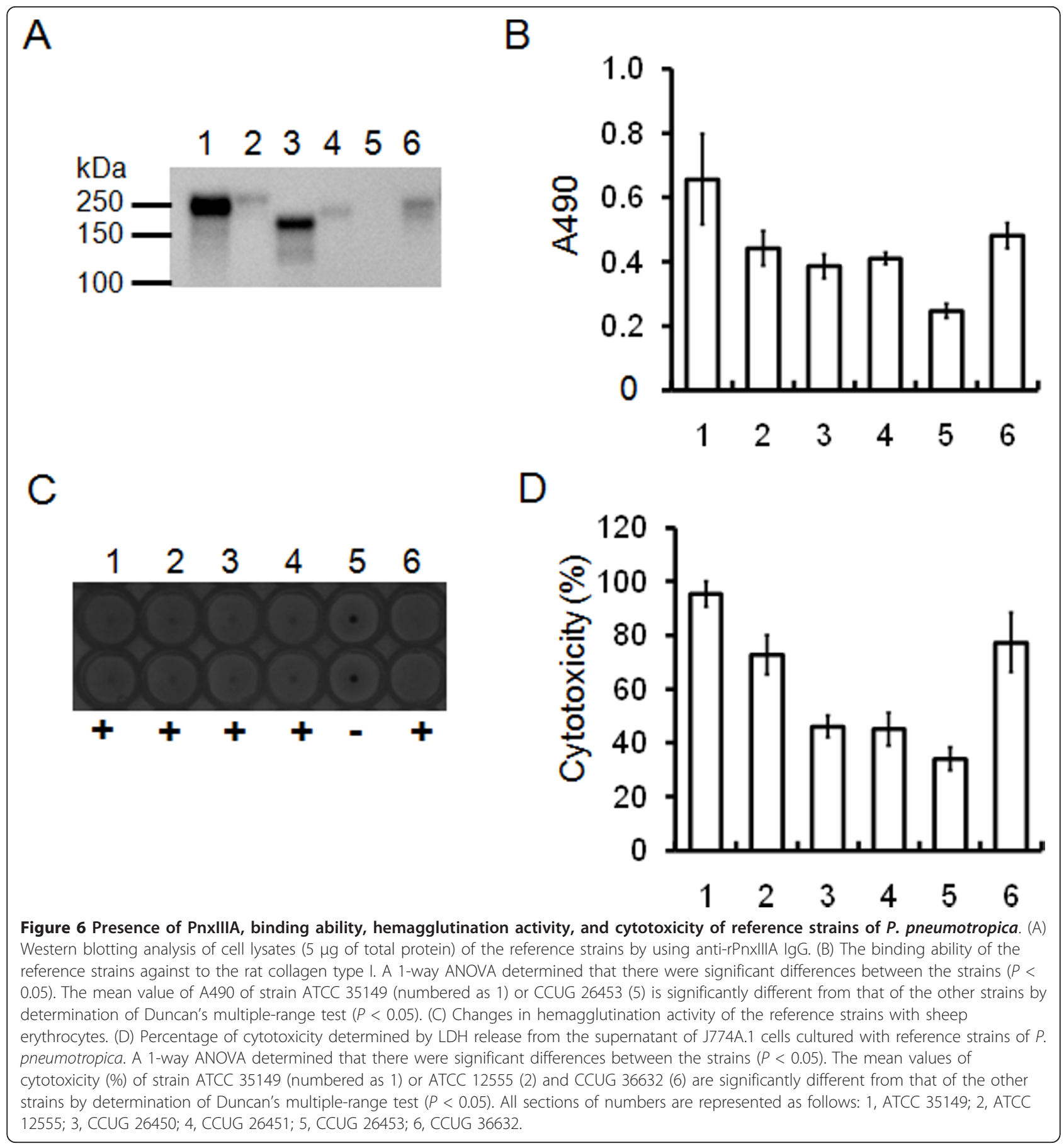

large repeat sequences contained regions that were partially similar to several groups of bacterial Ig-like domains, including groups 1,2 , and 4 . Many Ig-like domains that belong to these groups are indicated to form an Ig-like fold and are reportedly present in bacterial cell-surface proteins such as intimins and invasins [37-40]. The other groups of Ig-like domains have also been suggested to form Ig-like folds and play in a role in adhesion to host cells, contributing to pathogenicity
[41]. In accordance with our experimental results, these sequences are indispensable for adherence to ECMs, and thus, the 3 large repeat sequences in PnxIIIA may be required for the pathogenicity of $P$. pneumotropica.

All RTX proteins in P. pneumotropica have only 3-7 RTX repeats and RTX-like sequences, and the numbers of the repeat sequence are fewer than those in the other highly toxic members of RTX toxin family $[15,17]$. For example, the toxicity of the B. pertussis RTX toxin CyaA is 
Table 1 Bacterial strains and plasmids used in this study

\begin{tabular}{|c|c|c|}
\hline Strain or plasmid & Description & $\begin{array}{l}\text { Source or } \\
\text { reference }\end{array}$ \\
\hline \multicolumn{3}{|l|}{ Strains } \\
\hline \multicolumn{3}{|c|}{ Pasteurella pneumotropica } \\
\hline ATCC 35149 & Type strain, biotype Jawetz, isolated from mouse lung & $\operatorname{ATCC}^{\mathrm{a}}[50]$ \\
\hline ATCC 12555 & Biotype Heyl, isolated from mouse & ATCC [51] \\
\hline CCUG 26450 & Biotype Jawetz, isolated from gerbil & CCUG $^{\mathrm{b}}$ \\
\hline CCUG 26451 & Biotype Jawetz, isolated from hamster & CCUG \\
\hline CCUG 26453 & Biotype Heyl, isolated from bird & CCUG \\
\hline CCUG 36632 & Biotype unknown, isolated from murine nose & CCUG \\
\hline \multicolumn{3}{|l|}{ Escherichia coli } \\
\hline $\mathrm{DH} 5 \alpha$ & Cloning strain & Stratagene \\
\hline TOP10 & Cloning strain & Invitrogen \\
\hline BL21-Al & Protein expression strain & Invitrogen \\
\hline TMU0812 & BL21-Al $\Delta h l y E:: \mathrm{Km}^{r}$ & [13] \\
\hline \multicolumn{3}{|l|}{ Plasmids } \\
\hline PTAC-1 & Cloning vector, $A p^{r}$ & $\begin{array}{l}\text { Biodynamics } \\
\text { Laboratory }\end{array}$ \\
\hline pENTR/SD/D-TOPO & Entry vector, $\mathrm{Km}^{\mathrm{r}}$ & Invitrogen \\
\hline pBAD-DEST49 & $\begin{array}{l}\text { Protein expression vector, } \mathrm{N} \text {-terminal fusions to thioredoxin tag and } \mathrm{C} \text {-terminal fusions to } \\
\qquad \text { six-Histidine tag, } \mathrm{Ap}^{\mathrm{r}}\end{array}$ & Invitrogen \\
\hline pET300/NT-DEST & Protein expression vector, $\mathrm{N}$-terminal fusions to six-Histidine tag, $A p^{r}$ & Invitrogen \\
\hline PTAC-PX3 & 0.5-kb pnx IIIA PCR fragment & This study \\
\hline pBAD-Pnx3A & Entire pnxIIIA gene cloned into pBAD-DEST49 & This study \\
\hline pBAD-Pnx3A 209 & 1.3-kb sequence of repeat 1 deleted from $\mathrm{pBAD}-\mathrm{Pn} \times 3 \mathrm{~A}$ & This study \\
\hline pBAD-Pnx3A 197 & $1.7-\mathrm{kb}$ sequence of repeats 2 and 3 deleted from $\mathrm{pBAD}-\mathrm{Pn} \times 3 \mathrm{~A}$ & This study \\
\hline pBAD-Pnx3A 151 & 3.0-kb sequence of repeats 1,2 , and 3 deleted from $\mathrm{pBAD}-\mathrm{Pn} \times 3 \mathrm{~A}$ & This study \\
\hline pET-Pnx3E & Entire pnxIIIE gene cloned into pET300/NT-DEST & This study \\
\hline
\end{tabular}

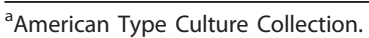

${ }^{\mathrm{b} C u l t u r e}$ Collection of the University of Göteborg.

reportedly activated by the coexpression of its accessory protein acyltransferase $\mathrm{CyaC}$, leading to the binding of B. pertussis to eukaryotic cells $[42,43]$. In the 3 RTX toxins in P. pneumotropica, none of the predicted acylation protein-coding genes were found in neighboring genes, and the acylation site was also not found in the primary structure of the proteins, indicating that the RTX proteins identified in P. pneumotropica have a structure that is unique to the RTX toxin family. Furthermore, the phenotypic and genetic characteristics of wild-type strain of $P$. pneumotropica were reportedly diversified with an increase in the number of isolates [44]. PnxIIIA is also assumed to be heterogenic and diversified among the P. pneumotropica strains. It is necessary to further clarify the relationships between the diversity and the role of PnxIIIA in P. pneumotropica infection.

\section{Conclusions}

In this study, we identified and characterized a third gene encoding the RTX exoprotein PnxIIIA. The results indicated that rPnxIIIA has cytotoxicity toward J774A.1 cells. Our results also implicate that PnxIIIA is localized on the cell surface and is related to adherence to the host ECMs and hemagglutination.

\section{Methods}

\section{Bacterial strains and plasmids}

The P. pneumotropica reference and E. coli strains and plasmids used in this study are listed in Table 1.

$p n x I I I A$ was first amplified using the primer pair pnx3A-pcr-f and pnx3A-pcr-r (Additional file 5 lists the oligonucleotide primers), and subsequently, the purified PCR product was used for a second amplification of pnxIIIA by using the primer pair pnx3A-protein-f and pnx3A-protein-r. The amplicon was cloned into an entry vector, $\mathrm{pENTR/SD/D-TOPO}$ vector (Invitrogen, Carlsbad, CA, USA), and subsequently recombined with the destination vector $\mathrm{pBAD}$ DEST49 (Invitrogen), yielding pBAD-Pnx3A. Mutant PnxIIIA expression vectors, pBAD-Pnx3 $\mathrm{A}_{209}$, pBAD$\mathrm{Pnx}_{3 \mathrm{~A}_{197} \text {, and pBAD-Pnx3A }} \mathrm{A}_{151}$, were also constructed as described below. 


\section{Bacterial and cell cultures and growth conditions}

All P. pneumotropica strains were maintained in a brainheart infusion medium (BD, Cockeysville, MD, USA) at $37^{\circ} \mathrm{C}$ and incubated for $48 \mathrm{~h}$. Transformed E. coli bacteria were grown at $37^{\circ} \mathrm{C}$ for $16 \mathrm{~h}$ in Luria-Bertani medium supplemented with $100 \mu \mathrm{g} / \mathrm{ml}$ ampicillin, $50 \mu \mathrm{g} / \mathrm{ml}$ kanamycin, $125 \mu \mathrm{M}$ 5-bromo-4-chloro-3indolyl- $\beta$-D-galactopyranoside, and $1 \mathrm{mM}$ isopropyl- $\beta$ $D$-thiogalactopyranoside, if required, to select and maintain recombinant $E$. coli. To induce gene expression in the recombinant $E$. coli, the cells were incubated at $37^{\circ} \mathrm{C}$ for $2-3 \mathrm{~h}$ until the optical density (OD, $600 \mathrm{~nm}$ ) reached 1.0. Subsequently, $0.1 \% \mathrm{~L}$-arabinose was added to the culture. During the induction of gene expression, the cell culture was incubated at room temperature (RT) for $16 \mathrm{~h}$.

J774A.1 mouse macrophage cells (JCRB9108) were provided by Health Science Research Resources Bank (Osaka, Japan). The J774A.1 cells were cultivated at $37^{\circ} \mathrm{C}$ in $5 \% \mathrm{CO}_{2}$ in Dulbecco's modified Eagle medium (DMEM; Wako, Osaka, Japan) supplemented with 10\% fetal bovine serum, $100 \mathrm{U}$ penicillin, and $100 \mu \mathrm{g} / \mathrm{ml}$ streptomycin sulfate.

\section{Nucleic acid extraction and purification}

Plasmid and genomic DNA were extracted according to the method described in a previous study [45].

\section{TA cloning, inverse PCR, and DNA sequencing}

A fragment of $p n x I I I A$ was amplified with the primer pair pnx2A-f and pnx2A-r by using Ex Taq (Takara Bio, Shiga, Japan), and the amplified product was purified using SUPREC-PCR (Takara Bio). The purified PCR amplicons were ligated with the pTAC-1 vector (Biodynamics Laboratory, Tokyo, Japan), and E. coli DH5 $\alpha$ was transformed with the resultant vectors. The clones were screened via blue-white selection and direct colony PCR by using the M13 primer pair. For inverse PCR, the genomic DNA of P. pneumotropica ATCC 35149 was digested with various restriction enzymes that recognized a 6-nucleotide sequence, and subsequently, the digestion product was self-ligated with T4 ligase (Takara Bio) and then used as an inverse PCR template. Inverse PCR was performed using gradient PCR to determine the optimum annealing temperature for a model DNA Engine PTC-200 (Bio-Rad Laboratories, Hercules, CA, USA). The PCR products were ligated with the pTAC-1 vector and screened to ensure the accuracy of sequencing. Cycle sequencing was performed using the BigDye terminator premix (Applied Biosystems, Foster City, CA, USA). The products of the sequencing reaction were analyzed using an ABI 310 or ABI 3730XL DNA analyzer (Applied Biosystems).

\section{Purification of recombinant Pnx proteins}

rPnxIIIA was extracted and purified from the cell culture of E. coli strain TMU0812 harboring pBAD-Pnx3A. The cultured cells were suspended in $20 \mathrm{mM}$ Tris- $\mathrm{HCl}$, $150 \mathrm{mM} \mathrm{NaCl}, 5 \mathrm{mM}$ imidazole, and $1 \mathrm{mM}$ 2-mercaptoethanol ( $\mathrm{pH} 8.0$, binding buffer); they were then broken by sonication. The sonicate was centrifuged at $7,000 \times g$ for $10 \mathrm{~min}$ and filtered using a $0.45-\mu \mathrm{m}$ filter unit (Millipore, Billerica, MA, USA). The supernatant was loaded onto a 1-ml His-trap HP affinity column (GE Healthcare, Amersham, UK) mounted on an ÁKTAprime plus fast protein liquid chromatography device (FPLC device; GE Healthcare), and chromatography was performed by running a program for histidinetagged protein purification according to the manufacturer's instructions. The collected sample was then eluted as a fraction in a buffer containing $20 \mathrm{mM}$ Tris$\mathrm{HCl}, 150 \mathrm{mM} \mathrm{NaCl}, 500 \mathrm{mM}$ imidazole, and $1 \mathrm{mM} 2-$ mercaptoethanol ( $\mathrm{pH}$ 8.0; elution buffer). Fractions that mainly contained rPnxIIIA were monitored and confirmed by SDS-PAGE. For purification of rPnxIIIE, E. coli BL21-AI cultures harboring pET-Pnx3E were extracted in a binding buffer containing $6 \mathrm{M}$ guanidine hydrochloride, and the extracts were purified with an elution buffer containing $6 \mathrm{M}$ urea, similar to the method used to purify rPnxIIIA. The solvent of rPnxIIIA and rPnxIIIE was exchanged to a buffer containing $20 \mathrm{mM}$ Tris- $\mathrm{HCl}$ and $150 \mathrm{mM} \mathrm{NaCl}$ by using FPLC and dialysis, respectively.

Purification of native rPnxIA and rPnxIIA was performed briefly according to previous described methods [13].

\section{Generation of deletion mutants of rPnxIIIA variants}

To compare the function of the unique repeat sequences in the rPnxIIIA variants, deletion mutant rPnxIIIA expression vectors were constructed. In brief, deletion mutant expression vectors pBAD-Pnx $3 \mathrm{~A}_{209}$, which lacked amino acid residues of a repeat sequence at position 287-735 (Figure 1B; Repeat 1), and pBADPnx3A 197 , which lacked amino acid residues of a repeat sequence at position 1097-1666, (Figure 1B; Repeats 2 and 3) were directly constructed using the wild-type protein expression vector $\mathrm{pBAD}-\mathrm{Pnx} 3 \mathrm{~A}$ as the template with primer pairs pnx3A-209-f and pnx3A-209-r and pnx3A-197-f and pnx3A-197-r, respectively. A PrimeSTAR Mutagenesis Basal Kit (Takara Bio) was used to create these deletion mutant expression vectors. Finally, pBAD-Pnx3A $\mathrm{A}_{151}$, which lacked both repeat sequences, was constructed with the primer pair pnx3A-197-f and pnx3A-197-r with pBAD-Pnx3A 209 as the PCR template. All the constructs were confirmed with DNA sequencing. The expression and purification of rPnxIIIA variants were performed in the same manner as that used for the wild-type rPnxIIIA. 


\section{Cytotoxicity assay}

The cytotoxicity of the recombinant Pnx proteins toward J774A.1 cells was determined via a LDH release assay that was performed according to the methods of Basler et al. [34] with minor modifications. Prior to incubation, the concentration of J774A.1 cells in a 96well plate was adjusted $1 \times 10^{5}$ cells per well. The cells were grown in fresh DMEM supplemented with $20 \mathrm{mM}$ $\mathrm{CaCl}_{2}$ and appropriate antibiotics. rPnxIIIA was added to the wells such that its concentrations were $0.1,0.5$, and $1.0 \mu \mathrm{g} / \mathrm{ml}$ of the final concentrations. The plate was incubated at $37^{\circ} \mathrm{C}$ in $5 \% \mathrm{CO}_{2}$ for up to $24 \mathrm{~h}$. LDH release from the J774A.1 cells was measured at 1, 2, 4, 6,12 , and $24 \mathrm{~h}$ by using the supernatant from the treated cells; a cytotoxicity detection kit (Roche Diagnostics, Mannheim, Germany) was used for this purpose. For the comparison of cytotoxicity among rPnxIA, rPnxIIA, and rPnxIIIA, $1.0 \mu \mathrm{g} / \mathrm{ml}$ of each recombinant protein was incubated with the J774A.1 cells for $4 \mathrm{~h}$. Thereafter, LDH release from the J774A.1 cells was measured. Furthermore, to assess the effect of existence of CD11a on inhibition of rPnxIIIA-induced cytolysis, LDH release from the J774A.1 cells with the addition of $1.0 \mu \mathrm{g} / \mathrm{ml}$ rPnxIIIA with or without $1.0 \mu \mathrm{g} / \mathrm{ml}$ anti-CD11a rat MAb (Abcam, Cambridge, UK), which cross-reacts with the $\alpha$ subunit of mouse CD11 as a neutralizing antibody, was measured after $2,6,12$, and $24 \mathrm{~h}$ of incubation as described above. To assess the cytotoxicity of P. pneumotropica reference strains toward J774A.1 cells, a whole bacterial cell cytotoxicity assay was performed briefly according to the methods of Kehl-Fie et al. [46]. The results were reported as the percentage of $\mathrm{LDH}$ released from all the lysed cells. The experiments were repeated in triplicate.

\section{ECM-binding assay}

ELISA was used to determine the binding of rPnxIIIA variants to components of rodent ECMs. In brief, a 96well microtiter plate coated with rat collagen type I (BD BioCoat, BD) was used for the binding assay of rat collagen type I, and rat collagen type II (Chondrex, Redmond, WA, USA), mouse collagen type IV (BD), and mouse laminin (BD) were differently coated on a 96well microplate (As one, Osaka, Japan) according to the manufacturer's instructions. ELISA was performed with a protein detector AP microwell kit (KPL, Gaithersburg, MD, USA), anti-6× Histidine tag monoclonal antibody (Biodynamics laboratory), and rPnxIIIA variants, the concentrations of which were adjusted to $0.5-50 \mu \mathrm{g} / \mathrm{ml}$ of the final concentration.

For the whole-cell binding assay of P. pneumotropica reference strains, precultured cells were adjusted the OD reached 1.0 and incubated on a 96-well microtiter plate coated with rat collagen type $\mathrm{I}(\mathrm{BD})$ at $37^{\circ} \mathrm{C}$ for $24 \mathrm{~h}$.
Thereafter, the plate was briefly washed and stained with $0.1 \%$ safranin, according to the method of Davey and Duncan [47]. The quantification of adherent cells was determined by measuring the A490 with a plate reader.

\section{Hemagglutination and hemolytic assay}

Defibrinated sheep blood was obtained from Nippon Bio-Test Laboratories (Tokyo, Japan) and washed 3 times with sterilized phosphate-buffered saline (PBS) prior to conducting the assays. Hemagglutination activity was determined in V-cut bottom 96-well microtiter plates (Corning, Horseheads, NY, USA). Fifty micro milliliters of diluted rPnxIIIA variants or overnight cultures of $P$. pneumotropica reference strains were added to wells containing $2 \%$ sheep erythrocytes. The plate was incubated at RT for $1 \mathrm{~h}$, and thereafter, the plate was imaged and visualized with a GeneGenius Bio Imaging System (Syngene, MD, USA). A hemolysis assay was performed according to a previously described method [13] that used 2\% sheep erythrocytes.

\section{Generation and purification of rabbit antisera}

In brief, crude rabbit antisera against the entire rPnxIIIA and rPnxIIIE proteins were prepared using the methods of Schaller et al. [48]. The crude antisera were further purified on an HiTrap rProtein A FF column (GE Healthcare) mounted on an FPLC device, and rabbit IgG was prepared for immunological experiments. The Institutional Animal Care and Use Committee of Tokyo Medical University approved all of the animal experimental procedures described here.

\section{Fractionation of bacterial cell culture}

Fractionation of the OM fraction, IM fraction, and soluble cell (SC) components was performed according to the methods of Valle et al. [49]. P. pneumotropica ATCC 35149 cells in the mid-log phase were harvested, resuspended in $10 \mathrm{mM}$ HEPES ( $\mathrm{pH} 7.5$ ) with $50 \mathrm{mM} \mathrm{NaCl}$ and $0.1 \mathrm{mg} / \mathrm{ml}$ lysozyme, and disrupted by sonication. The sonicate was centrifuged at 7,000 $\times g$ for $10 \mathrm{~min}$, and subsequently, the supernatant was centrifuged at 100,000 $\times g$ for 1 h by using a Beckman Optima TL Tabletop Centrifuge (Beckman Coulter, Brea, CA, USA). The supernatant was used as the $\mathrm{SC}$ fraction, and the pellet containing the bacterial membrane was resuspended in a buffer containing $0.5 \%$ sarkosyl ( $N$-laurylsarcosine) and allowed to stand for $30 \mathrm{~min}$ at RT. The sarkosyl-soluble fraction was centrifuged at $100,000 \times g$ for $1 \mathrm{~h}$. The supernatant was used as the IM fraction, and the pellet was resuspended in a $500 \mu \mathrm{l}$ of $10 \mathrm{mM}$ HEPES ( $\mathrm{pH} 7.5)$ with $50 \mathrm{mM} \mathrm{NaCl}, 1 \%$ sarkosyl, and $10 \mathrm{mM}$ EDTA and used as the OM fraction. To prepare a cell-free supernatant, the P. pneumotropica ATCC 35149 culture in the mid-log phase was centrifuged at 7,000 $\times$ g for $10 \mathrm{~min}$, 
and the supernatant was filtered through a $0.22-\mu \mathrm{m}$ pore size filter (Millipore) followed by a $0.45-\mu \mathrm{m}$ pore size filter (Millipore). The filtrate was ultrafiltrated at $1000 \times g$ for $20 \mathrm{~min}$ by using AmiconUltra-15 (Millipore). The resultant solution was used as the ultrafiltrated culture supernatant (UC) fraction. For SDS-PAGE analysis, the concentration of the SC, IM, OM, and UC samples were adjusted to $0.2 \mathrm{mg} / \mathrm{ml}$, and $10 \mu \mathrm{l}$ of each sample were subjected to $10 \%$ SDS-PAGE.

\section{Cross-linking and pull-down assay}

To determine the in vitro interaction of rPnxIIIA and rPnxIIIE, chemical cross-linking and IP were performed. A cross-linker for soluble proteins, bis[sulfosuccinimidyl] suberate- $\mathrm{d}_{0}\left(\mathrm{BS}^{3}-\mathrm{d}_{0}\right.$; Thermo Fisher Scientific, Waltham, MA, USA), was used for the cross-linking reaction of rPnxIIIA and rPnxIIIE according to the manufacturer's instructions. To terminate the cross-linking reaction, $20 \mathrm{mM} \mathrm{NH}_{4} \mathrm{HCO}_{3}$ was added. Thereafter, a mixed solution was subjected to IP by using an IP kit, Dynabeads Protein G (Invitrogen), and rabbit IgG against rPnxIIIA according to the manufacturer's instructions. The resultant solution was subjected to SDS-PAGE, and the interaction of rPnxIIIA with rPnxIIIA or rPnxIIIE was detected by Western blotting as described below.

\section{Western blotting and Southern hybridization}

Fractions of the P. pneumotropica cell culture, IP-treated sample, and cell lysates of $P$. pneumotropica reference strains were analyzed by Western blotting by using antirPnxIIIA IgG $(1: 20,000)$ or anti-rPnxIIIE IgG $(1: 20,000)$, followed by SDS-PAGE separation. Anti-rabbit IgG antibody conjugated to horseradish peroxidase (HRP; Thermo Fisher Scientific) for anti-rPnxIIIA IgG was used as secondary antibodies at a dilution of 1:50,000. To detect hybridization signals, the Femto Western chemiluminescence reagent (Thermo Fisher Scientific) was used as a substrate for HRP.

For Southern hybridization, digoxigenin-11-dUTPlabeled pnxIIIA probes were generated using the primerpair pnx3A-probe-f and pnx3A-probe-r and the genomic DNA of $P$. pneumotropica ATCC 35149. The genomic DNAs of the reference strains were digested with HindIII and loaded on agarose gels. The hybridization and detection protocol used has been described previously [13].

\section{Immunoelectron microscopy}

Bacterial cells were fixed with $4 \%(\mathrm{w} / \mathrm{v})$ paraformaldehyde, $0.25 \%(\mathrm{v} / \mathrm{v})$ glutaraldehyde, and $5 \%$ sucrose in $1.5 \mathrm{ml}$ of $0.1 \mathrm{M}$ phosphate buffer ( $\mathrm{pH} 7.4$ ) for $2 \mathrm{~h}$ at $4^{\circ} \mathrm{C}$. The cells were harvested at $1000 \times g$ for $10 \mathrm{~min}$. The pellets were then rinsed with the same buffer and dehydrated by passing them through an ethanol series. Samples were embedded in LR-white resin. Thin sections were placed in PBS with $5 \%$ bovine serum albumin (BSA) for $30 \mathrm{~min}$ at RT and then incubated with rabbit anti-PnxIIIA IgG diluted to 1:100 with 1\% BSA in PBS for $4 \mathrm{~h}$ at RT. The sections were washed 3 times in PBS and incubated with goat anti-rabbit IgG conjugated with 10-nm immunogold particles (BBInternational, Cardiff, UK) diluted to 1:50 with 5\% BSA in PBS for $1 \mathrm{~h}$. The sections were subsequently stained with uranyl acetate and lead citrate and viewed under a JEOL JEM-1200EX electron microscope (JEOL, Tokyo, Japan) at $80 \mathrm{kV}$.

\section{Nucleic acid accession numbers}

The nucleotide sequences of pnxIIIE, pnxIIIA, pnxIIIB, $p n x I I I D$, and tolC were deposited in GenBank through DNA Data Bank of Japan, and the assigned accession numbers were AB568084, AB568085, AB568086, AB568087, and AB568088, respectively.

\section{Additional material}

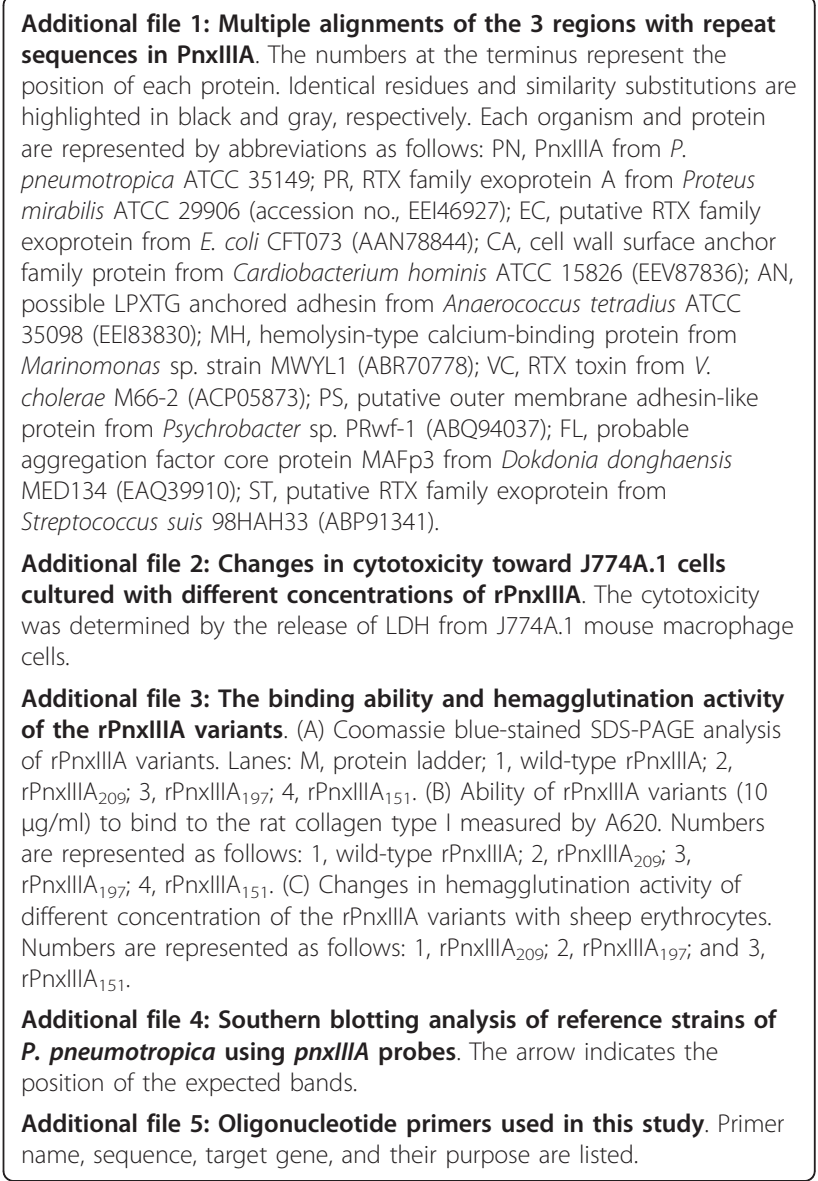

\section{Acknowledgements}

This study was partially supported by a grant-in-aid (20700369) from the Ministry of Education, Culture, Sports, Science, and Technology, Japan. 


\section{Author details}

${ }^{1}$ Animal Research Center, Tokyo Medical University, Shinjuku, Tokyo, Japan. ${ }^{2}$ Department of Microbiology, Tokyo Medical University, Shinjuku, Tokyo, Japan. ${ }^{3}$ Department of Histology and Neuroanatomy, Tokyo Medical University, Shinjuku, Tokyo, Japan. ${ }^{4}$ Laboratory of Experimental Animal Science, Nippon Veterinary and Life Science University, 1-7-1 Musashino, Tokyo, Japan.

\section{Authors' contributions}

HS performed all the examinations and coordinated the study. HI and TM supervised the experimental conditions. TS, KK, and KS analyzed immunoelectron microscopy data and supported the study. SS and HA performed the purification of recombinant proteins and cytotoxicity assays. All authors read and approved the final manuscript.

Received: 16 December 2010 Accepted: 17 March 2011 Published: 17 March 2011

\section{References}

1. Brennan PC, Fritz TE, Flynn RJ: Role of Pasteurella pneumotropica and Mycoplasma pulmonis in murine pneumonia. J Bacteriol 1969, 97:337-349.

2. Patten CC Jr, Myles MH, Franklin CL, Livingston RS: Perturbations in cytokine gene expression after inoculation of $\mathrm{C57BL} / 6$ mice with Pasteurella pneumotropica. Comp Med 2010, 60:18-24.

3. Macy JD Jr, Weir EC, Compton SR, Shlomchik MJ, Brownstein DG: Dual infection with Pneumocystis carinii and Pasteurella pneumotropica in B cell-deficient mice: diagnosis and therapy. Comp Med 2000, 50:49-55.

4. Marcotte $H$, Levesque D, Delanay K, Bourgeault A, de la Durantaye R, Brochu S, Lavoie MC: Pneumocystis carinii infection in transgenic B celldeficient mice. J Infect Dis 1996, 173:1034-1037.

5. Chapes SK, Mosier DA, Wright AD, Hart ML: MHCII, TIr4 and Nramp1 genes control host pulmonary resistance against the opportunistic bacterium Pasteurella pneumotropica. J Leukoc Biol 2001, 69:381-386.

6. Hart ML, Mosier DA, Chapes SK: Toll-like receptor 4-positive macrophages protect mice from Pasteurella pneumotropica-induced pneumonia. Infect Immun 2003, 71:663-670

7. Artwohl JE, Flynn JC, Bunte RM, Angen O, Herold KC: Outbreak of Pasteurella pneumotropica in a closed colony of STOCK-Cd28 ${ }^{\text {(tm 1Mak) }}$ mice. Contemp Top Lab Anim Sci 2000, 39:39-41.

8. Goelz MF, Thigpen JE, Mahler J, Rogers WP, Locklear J, Weigler BJ, Forsythe DB: Efficacy of various therapeutic regimens in eliminating Pasteurella pneumotropica from the mouse. Lab Anim Sci 1996, 46:280-285.

9. Sasaki H, Kawamoto E, Kunita S, Yagami K: Comparison of the in vitro susceptibility of rodent isolates of Pseudomonas aeruginosa and Pasteurella pneumotropica to enrofloxacin. J Vet Diagn Invest 2007, 19:557-560.

10. Ueno Y, Shimizu R, Nozu R, Takahashi S, Yamamoto M, Sugiyama F, Takakura A, Itoh T, Yagami K: Elimination of Pasteurella pneumotropica from a contaminated mouse colony by oral administration of Enrofloxacin. Exp Anim 2002, 51:401-405.

11. Boot R, Thuis H, Teppema JS: Hemagglutination by Pasteurellaceae isolated from rodents. Zentralb/ Bakteriol 1993, 279:259-273.

12. Hooper A, Sebesteny A: Variation in Pasteurella pneumotropica. J Med Microbiol 1974, 7:137-140.

13. Sasaki H, Kawamoto E, Tanaka Y, Sawada T, Kunita S, Yagami K: Identification and characterization of hemolysin-like proteins similar to RTX toxin in Pasteurella pneumotropica. J Bacterio/ 2009, 191:3698-3705.

14. Frey J: RTX toxin-determined virulence of Pasteurellaceae. In Pasteurellaceae. Edited by: Kuhnert P, Christensen H. Norwich: Horizon Scientific Press; 2008:133-144.

15. Frey J, Kuhnert P: RTX toxins in Pasteurellaceae. Int J Med Microbiol 2002, 292:149-158.

16. Trucksis M, Galen JE, Michalski J, Fasano A, Kaper JB: Accessory cholera enterotoxin (Ace), the third toxin of a Vibrio cholerae virulence cassette. Proc Natl Acad Sci USA 1993, 90:5267-5271.

17. Welch RA: RTX toxin structure and function: a story of numerous anomalies and few analogies in toxin biology. Curr Top Microbiol Immunol 2001, 257:85-111.
18. Balashova NV, Diaz R, Balashov SV, Crosby JA, Kachlany SC: Regulation of Aggregatibacter (Actinobacillus) actinomycetemcomitans leukotoxin secretion by iron. J Bacteriol 2006, 188:8658-8661.

19. Gallant CV, Sedic M, Chicoine EA, Ruiz T, Mintz KP: Membrane morphology and leukotoxin secretion are associated with a novel membrane protein of Aggregatibacter actinomycetemcomitans. J Bacteriol 2008, 190:5972-5980.

20. Kachlany SC, Fine DH, Figurski DH: Secretion of RTX leukotoxin by Actinobacillus actinomycetemcomitans. Infect Immun 2000, 68:6094-6100

21. Venketaraman V, Lin AK, Le A, Kachlany SC, Connell ND, Kaplan JB: Both leukotoxin and poly-N-acetylglucosamine surface polysaccharide protect Aggregatibacter actinomycetemcomitans cells from macrophage killing. Microb Pathog 2008, 45:173-180.

22. Ramjeet M, Cox AD, Hancock MA, Mourez M, Labrie J, Gottschalk M, Jacques M: Mutation in the LPS outer core biosynthesis gene, galU, affects LPS interaction with the RTX toxins ApxI and Apxll and cytolytic activity of Actinobacillus pleuropneumoniae serotype 1. Mol Microbiol 2008, 70:221-235.

23. Fullner KJ, Boucher JC, Hanes MA, Haines GK, Meehan BM, Walchle C, Sansonetti PJ, Mekalanos JJ: The contribution of accessory toxins of Vibrio cholerae $\mathrm{O} 1 \mathrm{El}$ Tor to the proinflammatory response in a murine pulmonary cholera model. J Exp Med 2002, 195:1455-1462.

24. Fullner KJ, Mekalanos JJ: In vivo covalent cross-linking of cellular actin by the Vibrio cholerae RTX toxin. EMBO J 2000, 19:5315-5323.

25. Kudryashov DS, Durer ZA, Ytterberg AJ, Sawaya MR, Pashkov I, Prochazkova K, Yeates TO, Loo RR, Loo JA, Satchell KJ, Reisler E: Connecting actin monomers by iso-peptide bond is a toxicity mechanism of the Vibrio cholerae MARTX toxin. Proc Natl Acad Sci USA 2008, 105:18537-18542.

26. Olivier V, Haines GK III, Tan Y, Satchell KJ: Hemolysin and the multifunctional autoprocessing RTX toxin are virulence factors during intestinal infection of mice with Vibrio cholerae El Tor 01 strains. Infect Immun 2007, 75:5035-5042.

27. Altschul SF, Madden TL, Schaffer AA, Zhang J, Zhang Z, Miller W, Lipman DJ: Gapped BLAST and PSI-BLAST: a new generation of protein database search programs. Nucleic Acids Res 1997, 25:3389-3402.

28. Finn RD, Mistry J, Schuster-Bockler B, Griffiths-Jones S, Hollich V, Lassmann T, Moxon S, Marshall M, Khanna A, Durbin R, Eddy SR, Sonnhammer EL, Bateman A: Pfam: clans, web tools and services. Nucleic Acids Res 2006, 34:D247-D251

29. Welch RA, Burland V, Plunkett G, Redford P, Roesch P, Rasko D, Buckles EL, Liou SR, Boutin A, Hackett J, Stroud D, Mayhew GF, Rose DJ, Zhou S, Schwartz DC, Perna NT, Mobley HL, Donnenberg MS, Blattner FR: Extensive mosaic structure revealed by the complete genome sequence of uropathogenic Escherichia coli. Proc Natl Acad Sci USA 2002, 99:17020-17024

30. Ambagala TC, Ambagala AP, Srikumaran S: The leukotoxin of Pasteurella haemolytica binds to $\beta_{2}$ integrins on bovine leukocytes. FEMS Microbiol Lett 1999, 179:161-167.

31. Jeyaseelan S, Hsuan SL, Kannan MS, Walcheck B, Wang JF, Kehrli ME, Lally ET, Sieck GC, Maheswaran SK: Lymphocyte function-associated antigen 1 is a receptor for Pasteurella haemolytica leukotoxin in bovine leukocytes. Infect Immun 2000, 68:72-79.

32. Lally ET, Kieba IR, Sato A, Green CL, Rosenbloom J, Korostoff J, Wang JF, Shenker BJ, Ortlepp S, Robinson MK, Billings PC: RTX toxins recognize a $\beta_{2}$ integrin on the surface of human target cells. J Biol Chem 1997, 272:30463-30469.

33. Lloyd AL, Henderson TA, Vigil PD, Mobley HL: Genomic islands of uropathogenic Escherichia coli contribute to virulence. J Bacteriol 2009 191:3469-3681.

34. Basler M, Masin J, Osicka R, Sebo P: Pore-forming and enzymatic activities of Bordetella pertussis adenylate cyclase toxin synergize in promoting lysis of monocytes. Infect Immun 2006, 74:2207-2214.

35. Linhartová I, Bumba L, Mašín J, Basler M, Osička R, Kamanová J, Procházková K, Adkins I, Hejnová-Holubová J, Sadílková L, Morová J, Sebo P: RTX proteins: a highly diverse family secreted by a common mechanism. FEMS Microbiol Rev 2010, 34:1076-1112.

36. Kieba IR, Fong KP, Tang HY, Hoffman KE, Speicher DW, Klickstein LB, Lally ET: Aggregatibacter actinomycetemcomitans leukotoxin requires $\beta$ - 
sheets 1 and 2 of the human CD11a $\beta$-propeller for cytotoxicity. Cell Microbiol 2007, 9:2689-2699.

37. Frankel G, Phillips AD, Trabulsi LR, Knutton S, Dougan G, Matthews S: Intimin and the host cell-is it bound to end in Tir(s)? Trends Microbiol 2001, 9:214-218.

38. Kelly G, Prasannan S, Daniell S, Fleming K, Frankel G, Dougan G, Connerton I, Matthews S: Structure of the cell-adhesion fragment of intimin from enteropathogenic Escherichia coli. Nat Struct Biol 1999, 6:313-318.

39. Luo Y, Frey EA, Pfuetzner RA, Creagh AL, Knoechel DG, Haynes CA, Finlay BB, Strynadka NC: Crystal structure of enteropathogenic Escherichia coli intimin-receptor complex. Nature 2000, 405:1073-1077.

40. Sukumar N, Mishra M, Sloan GP, Ogi T, Deora R: Differential Bvg phasedependent regulation and combinatorial role in pathogenesis of two Bordetella paralogs, BipA and BcfA. J Bacteriol 2007, 189:3695-3704.

41. Bentley SD, Maiwald M, Murphy LD, Pallen MJ, Yeats CA, Dover LG, Norbertczak HT, Besra GS, Quail MA, Harris DE, von Herbay A, Goble A, Rutter S, Squares R, Squares S, Barrell BG, Parkhill J, Relman DA: Sequencing and analysis of the genome of the Whipple's disease bacterium Tropheryma whipplei. Lancet 2003, 361:637-644.

42. Hackett M, Guo L, Shabanowitz J, Hunt DF, Hewlett EL: Internal lysine palmitoylation in adenylate cyclase toxin from Bordetella pertussis. Science 1994, 266:433-435.

43. Masin J, Basler M, Knapp O, El-Azami-El-Idrissi M, Maier E, Konopasek I, Benz R, Leclerc C, Sebo P: Acylation of lysine 860 allows tight binding and cytotoxicity of Bordetella adenylate cyclase on CD11b-expressing cells. Biochemistry 2005, 44:12759-12766.

44. Sasaki H, Kawamoto E, Tanaka Y, Sawada T, Kunita S, Yagami K: Comparative analysis of Pasteurella pneumotropica isolates from laboratory mice and rats. Antonie Van Leeuwenhoek 2009, 95:311-317.

45. Sambrook J, Russell D: Molecular cloning: A laboratory manual. 3 edition. Cold Spring Laboratory, New York; 2001

46. Kehl-Fie TE, St Geme JW III: Identification and characterization of an RTX toxin in the emerging pathogen Kingella kingae. J Bacteriol 2007, 189:430-436.

47. Davey ME, Duncan MJ: Enhanced biofilm formation and loss of capsule synthesis: deletion of a putative glycosyltransferase in Porphyromonas gingivalis. J Bacteriol 2006, 188:5510-5523.

48. Schaller A, Kuhn R, Kuhnert P, Nicolet J, Anderson TJ, Maclnnes Jl, Segers RP, Frey J: Characterization of apxIVA, a new RTX determinant of Actinobacillus pleuropneumoniae. Microbiology 1999, 145:2105-2116.

49. Valle J, Mabbett AN, Ulett GC, Toledo-Arana A, Wecker K, Totsika M, Schembri MA, Ghigo JM, Beloin C: UpaG, a new member of the trimeric autotransporter family of adhesins in uropathogenic Escherichia coli. J Bacteriol 2008, 190:4147-4161

50. Jawetz E: A pneumotropic Pasteurella of laboratory animals. I. Bacteriological and serological characteristics of the organism. J Infect Dis 1950, 86:172-183.

51. Gray DF, Campbell AL: The use of chloramphenicol and foster mothers in the control of natural pasteurellosis in experimental mice. Aust J Exp Biol Med Sci 1953, 31:161-165.

doi:10.1186/1471-2180-11-55

Cite this article as: Sasaki et al:: Molecular and virulence characteristics of an outer membrane-associated RTX exoprotein in Pasteurella pneumotropica. BMC Microbiology 2011 11:55.

\section{Submit your next manuscript to BioMed Central and take full advantage of:}

- Convenient online submission

- Thorough peer review

- No space constraints or color figure charges

- Immediate publication on acceptance

- Inclusion in PubMed, CAS, Scopus and Google Scholar

- Research which is freely available for redistribution

Submit your manuscript at www.biomedcentral.com/submit
Biomed Central 